\title{
A INTERVENÇÃO JUDICIAL \\ COMO MEIO EXECUTIVO \\ PARA A TUTELA DOS \\ NOVOS DIREITOS
}

\section{Lucas de Brandão e Mattos}

Aluno do $9^{\circ}$ semestre do curso de Direito da FA7, orientado pela profa. Ms. Isabel Cecília de Oliveira Bezerra lucasbmattos@hotmail.com isabel.bezerra@agu.gov.br

Sumário: Introdução. 1. Efetividade do processo, direito material. 2. Os "novos direitos" e os novos desafios da execução. 3. Meios executivos. 4. A intervenção judicial. 5. A intervenção judicial na execução dos novos direitos. Considerações finais. Referências.

Resumo: $O$ estudo tem por finalidade trazer luzes a um meio executivo pouco conhecido e aplicado no direito pátrio, apesar de regulamentado em lei: a intervenção judicial. Visa a demonstrar a efetividade de sua aplicação, principalmente no que concerne aos chamados "novos direitos", que impõem obrigações de fazer ou não fazer complexas e de trato sucessivo, sendo, o executado, muitas vezes, pessoa jurídica para a qual poderá ser nomeado interventor que cumprirá os atos.

Palavras-chave: Intervenção Judicial. Efetividade da Execução. Novos Direitos. Atipicidade dos Meios Executivos.

\section{INTRODUÇÃo}

Inegavelmente, o direito processual sofre nos dias atuais uma remodelação à luz da teoria dos direitos fundamentais, modificando nossos conceitos de acesso à justiça e efetividade da tutela jurisdicional.

Os "novos direitos" são os frutos das novas legislações surgidas no contexto de transição para o pós-positivismo, dos quais são exemplos, as legislações protetoras da criança e do adolescente, do idoso, do meio ambiente, do consumidor, dentre outros, como também os direitos já postos anteriormente, mas que agora são vistos com outros olhos pelo ordenamento jurídico. Desse modo, uma gama maior e antes impensável de situações torna-se passível de proteção por meio do processo que deve, então, assumir feições que garantam aquilo que está posto na norma material. 
O fato de ser o nosso processo civil pautado no individualismo das demandas gera muitos problemas para a persecução judicial desses direitos que, na maioria das vezes, por seu caráter metaindividual, são buscados na forma de ações coletivas.

Dentro dessa perspectiva, a execução é uma fase crítica para a afirmação desses direitos que dependem essencialmente de sua tutela específica, pois a conversão em pecúnia desvirtuaria toda a finalidade da norma.

A ausência de meios executivos idôneos à execução desses direitos é, com certeza, um dos grandes problemas da efetividade do direito processual atualmente.

O presente estudo encarrega-se, assim, de analisar as questões postas, bem como a intervenção judicial, medida prevista nos arts. 69 a 78 da lei antitruste (Lei $n^{\circ} 8.8884 / 94$ ), quanto ao seu cabimento, adequação e efetividade como meio executivo para tutela adequada dos "novos direitos".

\section{Efetividade do Processo e Direito Material}

Da era romana ao Direito Francês do Código de Napoleão o processo não era considerado autônomo em relação ao direito material. A ação era conceituada em correspondência ao direito material, sistema de ações típicas, o que gerava muitas lacunas e uma ciência processual pouco desenvolvida.

Na primeira metade do século XX, a doutrina processual italiana de Chiovenda, Liebman, Carnelluti, Calamandrei, dentre outros, cunhou o processo civil como o conhecemos, fundado na autonomia e abstração do direito de ação, sobre o qual gravita o direito processual, agora se julgando completamente liberto do direito material e consolidado como ciência.

O resultado desta mudança de paradigma na tutela dos direitos é definido por Proto Pisani, nas palavras de Luiz Guilherme Marinoni:

[....] na época em que as ações eram típicas, as tutelas específicas e ressarcitórias ficavam a elas vinculadas, mas, depois da conquista da autonomia da ação - de sua desvinculação do direito material -, as tutelas específicas, porque ficaram subordinadas a uma ação autônoma e atípica - passível de ser utilizada para a obtenção de qualquer tipo de tutela -, passaram a depender apenas das técnicas processuais. (MARINONI, 2006, p. 841).

Portanto, dentro do sistema processual tradicional, o alcance da tutela específica dependia das técnicas processuais disponíveis que, no caso da execução, consistem, principalmente, nos meios executivos disponíveis à efetivação do direito posto em juízo. 
Neste sentido, a tutela dos direitos era, quase sempre, reduzida ao ressarcimento pelo equivalente monetário. Assim, por mais diversos que fossem dois direitos materiais que demandavam proteção em juízo, passariam pelo mesmo procedimento e obteriam ao fim, em caso de procedência, o dinheiro advindo da expropriação dos bens do devedor.

Este modelo de processo é característico do Estado Liberal, fundado na igualdade meramente formal, na intangibilidade da vontade e na autodeterminação do mercado. Convivia-se com uma ação abstrata que se propunha a albergar quaisquer situações jurídicas. Porém, ao lado delas, a tipicidade das formas limitava o alcance da tutela específica. Assim ensina Marinoni:

O princípio da tipicidade das formas processuais não quer significar que as tutelas dos direitos estão subordinadas às ações típicas, mas sim que as técnicas processuais, capazes de dar corpo à ação autônoma e atípica, são apenas as que estão tipificadas na legislação. Tal princípio aceita a ideia de ação atípica, mas vincula a sua realização e desenvolvimento às formas processuais expressamente definidas em lei. (2006, p. 842)

Nos termos do atual Estado Constitucional, que gira em torno dos direitos fundamentais, o acesso à justiça assume a forma do "mais básico dos direitos humanos" (Capelleti Garth, 1988, p. 12), visto que é por meio dele que se torna possível alcançar todos os outros. Nesse sentido, escrevemos em outra oportunidade:

No Estado Democrático de Direito é papel do Judiciário a garantia dos direitos, pois é o poder para onde o cidadão recorrerá para garantir seus direitos, que não podem ser efetivados de mão própria. Assim, ao direito processual incumbe, como instrumento de efetivação, fazer-se coerente com o direito material. (MATTOS, 2009, p. 271)

Com este conceito em mente, fica claro que o processo tem um escopo único. Nas palavras de Chiovenda: "Il processo deve dare per quanto è possibile praticamente a chi ha um diritto tutto quello e proprio quello chegli ha diritto de conseguire". Portanto, somente a busca da tutela específica viabilizará o alcance desta "máxima coincidência possível" - expressão de Barbosa Moreira entre o mandamento do direito material e aquilo que será obtido através do processo.

As situações que ocorrem na vida e que são levadas ao processo são, por óbvio, atípicas. Seria, então, de uma inocência muito grande acreditar que formas típicas de técnicas para obtenção da tutela poderiam albergar a satisfação dos direitos e a efetividade da jurisdição. 
$\mathrm{O}$ mandamento do art. $5^{\circ}, \mathrm{XXXV}$ - acesso à justiça - não pode mais ser interpretado como o direito de ação consistente apenas em pedir e receber provimento de mérito, mas entendido como o direito fundamental à tutela jurisdicional adequada e efetiva. Na lição de Marinoni:

O direito fundamental à tutela jurisdicional efetiva é o direito de agir em juízo em busca da tutela jurisdicional efetiva do direito material, e isso está a quilômetros de distância dos antigos conceitos de ir a juízo e de direito de pedir a tutela jurisdicional. (2006, p. 860)

Faz-se necessário ao processualista moderno desprender-se do formalismo sem valor para ver o processo como o instrumento da efetividade do direito material (BEDAQUE, 2009).

O momento processual em que essas questões terão mais peso é, sem dúvida, na fase de execução, na qual os meios executivos utilizados têm a incumbência de ditar a satisfação do crédito nos termos do direito material, dependendo da sua idoneidade para obtê-la no caso concreto.

Para tanto, na perspectiva da instrumentalidade, o processualista deve sempre ter em mente o princípio da adequação na busca da efetividade da execução. Cabível a lição da processualista italiana Michelle Tarufo:

[....] a conexão entre situações substanciais carentes de tutela e técnicas de atuação executiva se coloca essencialmente na base do princípio da adequação, segundo o qual cada direito deve atuar através de um trâmite executivo mais idôneo e eficaz em função das necessidades do caso concreto. (1990, p.78)

Fixadas as premissas dessa necessária mutação adaptativa que o processo deve sofrer para que se torne adequado aos ditames do direito material e à persecução da tutela específica, caberá, pelo foco deste trabalho, um estudo acerca das características dos "novos direitos", que os fazem necessitar de uma tutela executiva diferenciada.

\section{Os "Novos Direitos" e os Novos Desafios da Execução}

Não podemos negar que a expressão "novos direitos" pode ser bastante controvertida, sendo preferência de muitos a denominação de direitos metaindividuais ou difusos lato sensu. Porém, a expressão "novos direitos" nos parece ganhar maior amplitude e abstração, visto que pode acolher tanto os metaindividuais, quanto os direitos dos "ramos clássicos" do direito, como o civil e o trabalhista, mas eivados de uma constitucionalização que os eleva ao patamar 
de direitos fundamentais, de modo a atribuir-lhes nova forma e acesso a novos provimentos de caráter individual ou coletivo.

A origem destes direitos, ou desta nova perspectiva é, normalmente, situada na segunda metade do século XX, coincidindo com o período embrionário do neoconstitucionalismo, tendo especial relevância o movimento de acesso à justiça, que culminou no Projeto de Florença liderado por Mauro Capelleti. A segunda onda de reformas de acesso à justiça trouxe a jurisdição coletiva e normas materiais de cunho metaindividual. Sobre a necessidade de reforma dos instrumentos processuais ensinam Capelleti e Garth:

A concepção tradicional do processo civil não deixava espaço para proteção dos direitos difusos. O processo era visto apenas como um assunto entre duas partes, que se destinava à solução de uma controvérsia entre essas mesmas partes a respeito de seus próprios interesses individuais. Direitos que pertencessem a um grupo, ao público em geral ou a um segmento do público não se enquadravam bem nesse esquema. As regras determinantes da legitimidade, as normas de procedimento e a atuação dos juízes não eram destinadas a facilitar as demandas por interesses difusos intentadas por particulares $(1988$, p.50)

A gama de direitos abrangidos por esse conceito pode ser observada na lição de Michele Taruffo:

[.... novos direitos ou novas situações que entram no campo da "giustiziabilità". Esses direitos vão desde os direitos civis à tutela do meio ambiente até aos direitos contra a segregação racial e a tutela do consumidor, de problemas de família até relações de trabalho e direitos de presidiários de revisão das circunscrições eleitorais (1990, p. 75)

Em nosso ordenamento jurídico esses "novos direitos" representam direitos fundamentais, predominantemente da segunda e terceira gerações, visto que envolvem tanto direitos de cunho social, como também relativos à solidariedade. Mesmo aqueles não previstos expressamente na Constituição Federal adquirem essa feição constitucional por força do art. $5^{\circ}, \S 2^{\circ}$, da Carta Magna que eleva à categoria de fundamentais os direitos, visto que "decorrentes do regime e dos princípios por ela adotados", inseridos no conceito de "Bloco de Constitucionalidade", a que se refere Canotilho (2003). Sobre a mencionada feição constitucional desses direitos ensina Pedro Abi-Eçab:

No Brasil, a consolidação dos direitos difusos no plano normativo mostra que dúvidas não existem quanto ao fato de ter o país adentrado à terceira geração de direitos humanos - ao menos no que tange à positivação - marcada pelo caráter de solidariedade e que por fulcro a tutela de interesses maiores da sociedade, tais como a proteção do ambiente, das relações de consumo, da 
infância e da juventude, dos idosos, dos portadores de necessidades especiais, dos sem-terra, dos usuários do sistema de saúde, enfim, de uma universalidade indivisível como bem se observa pelos titulares do direito ao meio ambiente e à probidade administrativa: simplesmente todos os brasileiros e estrangeiros residentes no país. $(2008$, p. 279)

A atuação desses direitos no ordenamento jurídico acontece de forma diferenciada do raciocínio ordinário do jurista, compreendendo o ordenamento em tiras verticais, cada uma pertencendo a determinado âmbito do direito (tributário, civil, trabalhista etc.) que tem sua própria lógica de regras e princípios norteadores. Os "novos direitos" cortam essas tiras verticais horizontalmente, gerando o fenômeno denominado transversalidade dos "novos direitos" (Abi-Eçab, 2008), provocando a emanação desses microssistemas para o âmbito de todo o ordenamento jurídico, de forma a conferir novos formatos a antigos institutos e a criar princípios a serem observados e vertentes difusas dos direitos que antes só tinham feição individual.

Reconhecida a existência e o caráter especial dos novos direitos nos deparamos com as dificuldades de concretização dos mesmos. Assim alertam Capelleti e Garth:

É evidentemente uma tarefa difícil transformar esses direitos novos e muito importantes - para todas as sociedades modernas - em vantagens concretas para as pessoas comuns. Supondo que haja vontade política de mobilizar os indivíduos para fazerem valer seus direitos - ou seja, supondo que esses direitos sejam para valer - coloca-se a questão fundamental de como fazê-lo. (1988, p. 29)

As dificuldades de concretização vão desde o âmbito administrativo, pelo Poder Executivo na implementação de políticas públicas, até o Judiciário, visto que os instrumentos processuais foram forjados para as lides individuais e direitos de cunho eminentemente pecuniário. Inegável que em meio a essas questões está o terreno bastante conturbado da judicialização das políticas públicas e do papel do Judiciário na concretização dos direitos. Porém, a simples leitura de nossa Constituição e dos mencionados diplomas que trazem os "novos direitos", demonstra, pelo menos, que a repartição dos poderes não pode mais ser vista em um modelo rígido à moda de Montesquieu e que o papel do juiz no Estado Constitucional vai muito além da "boca da lei", estando bem mais próximo do "Juiz Hércules" de Dworkin (2007).

No que concerne à judicialização desses direitos, seja em sede de ação individual ou coletiva, a busca da tutela específica está ligada à própria eficácia do direito material, visto que a tutela ressarcitória deturpa todo o sentido protetivo dos valores ligados a esses direitos. Tal fato gera problemas no que concerne à execução desses direitos, demandando a adoção de meios executivos 
idôneos à persecução das mais diversas tutelas específicas possíveis, decorrente do direito material. Assim ensina Michele Taruffo:

[....] coloca, ao invés disso, em primeiro plano, situações que têm conteúdo exclusivamente ou prevalecentemente não pecuniário, criando, para essas, relevantes problemas de adaptação e extensão do sistema da tutela executiva. (1990, p. 75)

Nesse sentido, podemos mencionar algumas características dos "novos direitos", que devemos ter em mente no momento de procura do meio executivo mais adequado. Assim, é inestimável a classificação de Marcelo Lima Guerra:

Além disso, têm crescido, igualmente, o reconhecimento e a proteção aos chamados "novos direitos", isto é, situações não enquadráveis no clássico catálogo de direitos subjetivos. Esses novos direitos, apesar de bastante diversificados, apresentam importantes características comuns, a saber:

a) o conteúdo desses direitos corresponde, frequentemente, à prestação de fazer e de não fazer de trato sucessivo, isto é, que se realizam continuamente através de um período de tempo mais ou menos longo;

b) a violação deles conduz, quase sempre, a uma lesão irreparável (ou de difícil reparação);

c) revela-se totalmente inadequada, para proteção de tais direitos, a chamada tutela ressarcitória, genérica ou por equivalente, que consiste, como se sabe, na condenação ao pagamento de determinada quantia em dinheiro, ou seja, equivalente pecuniário da prestação inadimplida, impondo-se a obtenção da tutela específica desses direitos, isto é, da sua satisfação in natura, quando não realizados espontaneamente; [....] (2003, p. 115)

Pretendemos, nesse estágio, focar em situações que envolvem a condenação de pessoas jurídicas a prestações de fazer ou não fazer, de caráter complexo e de trato contínuo, nas quais a execução indireta é inefetiva. Assim ensina Michele Taruffo:

O problema surge em particular quando a execução da sentença comporta uma série de atividades complexas e diversificadas, ou, então, quando esta comporte o desenvolvimento e o controle de atividades continuadas ou destinadas a durar no tempo. (1990, p. 75)

\section{Meios Executivos}

O processo de execução, por sua natureza, tem, ou deve ter, "desfecho único", alcançado por meio de atividade coativa e de caráter 
jurisdicional, permitindo o controle do devido processo legal, no qual ocorre a invasão da esfera patrimonial ou pessoal do devedor com o objetivo único de concretizar o mandamento constante do título executivo. (GUERRA, 1999)

Para o alcance desse objetivo, o juiz dispõe de técnicas variadas de atividade coativa para efetivar a execução forçada, formando um sistema variável em cada ordenamento jurídico. Essas técnicas são conhecidas como meios executivos. O sistema dos meios executivos, ou "sistema de tutela executiva", varia conforme o ordenamento jurídico, como ensina Marcelo Guerra:

Convém adotar, na análise dos meios executivos previstos no direito brasileiro, terminologia já empregada por Proto Pisani no terreno das medidas cautelares. Assim, denominando-se sistema de tutela executiva o conjunto de meios executivos admitidos em um dado ordenamento, são concebíveis, no plano da mera possibilidade lógica, três modelos de tal sistema:

a) sistema típico: quando os meios executivos são tipificados em lei;

b) sistema atípico: quando os meios executivos são criados pelo órgão jurisdicional;

c) sistema misto: quando, ao lado dos meios executivos previstos em lei, pode o juiz, em caráter suplementar, criar outras. (2003, p.61)

O sistema original do Código Buzaid de 1973 era inteiramente típico, fincado nas ideias liberais da processualística clássica, trazendo clara preferência dos meios sub-rogatórios, substitutivos da vontade do devedor, em relação aos meios coercitivos, que procuram coagir o devedor a cooperar com a execução, pautada no dogma da intangibilidade da vontade humana. No atual CPC reformado, temos um sistema misto, no qual convivem técnicas típicas em conjunto com a possibilidade de criação judicial de meios idôneos à satisfação do credor no caso concreto.

Os sistemas de tutela executiva evoluem, invariavelmente, para a atipicidade dos meios executivos na proporcionalidade de seu comprometimento com o real acesso à justiça e a efetivação do direito material protegido em juízo.

É lícito definir, nessa perspectiva, que a efetividade da execução e da tutela jurisdicional está diretamente relacionada com a atipicidade dos meios executivos utilizados pelo magistrado para obter a tutela dos direitos.

O mandamento da efetividade do processo deve ser definido de modo que ao juiz estejam disponíveis todos os meios executivos, de cunho subrogatório ou coercitivo, que se mostrem proporcionais à obtenção da tutela e não sejam vedados pelo ordenamento jurídico com base em valores de proteção à dignidade do devedor, que prevaleçam na ponderação de valores no caso concreto (GUERRA, 2003). 
Não obstante tais considerações não dependerem de previsão infraconstitucional expressa, visto decorrerem diretamente do direito fundamental à tutela executiva, o legislador reformista foi sensível à necessidade da atipicidade dos meios executivos, insculpindo-a no reformado art. 461, $\S 5^{\circ}$, do Código de Processo Civil e no art. 84 do Código de Defesa do Consumidor, que assim dispõem:

Art. 461. Na ação que tenha por objeto o cumprimento de obrigação de fazer ou não fazer, o juiz concederá a tutela específica da obrigação ou, se procedente o pedido, determinará providências que assegurem o resultado prático equivalente ao do adimplemento.

[....]

$\S 5^{\circ}$ Para a efetivação da tutela específica ou a obtenção do resultado prático equivalente, poderá o juiz, de ofício ou a requerimento, determinar as medidas necessárias, tais como a imposição de multa por tempo de atraso, busca e apreensão, remoção de pessoas e coisas, desfazimento de obras e impedimento de atividade nociva, se necessário com requisição de força policial.

Art. 84. Na ação que tenha por objeto o cumprimento da obrigação de fazer ou não fazer, o juiz concederá a tutela específica da obrigação ou determinará providências que assegurem o resultado prático equivalente ao do adimplemento.

De fato, a atipicidade prevista na legislação só abrange, nos termos dos arts. 461 e 461-A do CPC, as obrigações de fazer, não fazer e dar coisa, o que é suficiente para o enfoque dado ao presente estudo, visto que a maioria das situações carentes de tutela albergadas pelos "novos direitos" consiste em obrigações das espécies mencionadas.

A doutrina tem atualmente dado maior enfoque aos meios coercitivos de execução, como a multa diária, mas isso pode levar o magistrado a novamente pensar a execução por meios típicos, só que agora com a inclusão da multa diária. Assim, não há uma ordem preferencial dos meios executivos e sim a análise do caso concreto para a identificação do meio executivo adequado.

É inegável que em grande parte das situações a cooperação do executado buscada através de meios executivos é bastante efetiva. Porém, quando o executado é uma pessoa jurídica, de direito público ou privado, e as obrigações são complexas, envolvendo uma série de ações e omissões conexas, e de trato sucessivo, sua efetividade resta prejudicada.

Para tanto, a intervenção judicial, estudada a seguir, pode ser cabível como meio executivo, de caráter sub-rogatório, para alcançar a tutela específica dos "novos direitos" e a consequente efetividade do processo, tratando, em seguida, de exemplos práticos de situações de necessidade da tutela e em que a intervenção se mostra profícua a tal fim. 


\section{A INTERVENÇÃo JUdiCIAL}

Como já apontado anteriormente, a intervenção judicial é medida prevista na lei antitruste - Lei $\mathrm{n}^{\circ} 8.884$ de 11 de junho de 1994 - como meio executivo, regulado nos arts. 69 a 78, que prevê a nomeação de interventor na pessoa jurídica condenada, atuando como representante do juiz e garantindo o cumprimento da obrigação constante da sentença.

No entanto, a aplicação da intervenção judicial não se restringe ao objeto da lei antitruste, visto que os já mencionados art. $461, \S 5^{\circ}$, do CPC e art. 84 do CDC, autorizam a utilização de quaisquer meios executivos adequados, tornando a intervenção ainda mais interessante, visto que tem seus limites fixados em lei, não ficando ao livre-arbítrio judicial o procedimento da medida executiva.

Julgamos que a melhor compreensão do instituto demanda uma busca por suas origens, que estão no direito comparado, principalmente nos ordenamentos do sistema common law, especialmente o direito norte-americano e o direito inglês.

No direito desses países, as ordens judiciais de caráter mandamental, denominadas injunctions, são uma técnica utilizada para condenar a prestações de fazer ou não fazer, tendo sua eficácia garantida pelos meios executivos mais diversos, desde a multa diária e a intervenção judicial, até a prisão civil (contempt of court). Sobre as injunctions assim ensina o professor Neil Andrews da Universidade de Cambridge:

The courts fashioned the injunction to induce recalcitrant parties to satisfy their legal duties. English judges are trusted to use their severe contempt of court powers against a person who breaches an injunction: fines, imprisonment, or seizure of personal or corporate assets. (2009, p. 166)

As medidas correspondentes às injunctions não têm previsão legal expressa, consistindo em poderes decorrentes da própria jurisdição e da submissão de todos ao direito, que se não puder ser efetivado estará sendo negado em sua essência. Como se tratam de poderes decorrentes da atividade jurisdicional são denominados de inherent powers. Assim ensina Marcelo Guerra:

Conclui-se, portanto, que os inherent powers dos juízes são "poderes instrumentais" de que se acham investidos esses mesmos juízes, no desempenho da função que lhes é própria e específica. Ao atribuir aos órgãos jurisdicionais poder para exercer a sua função específica, o ordenamento jurídico atribui também poderes para realizar todas as atividades e tomar todas as providências que assegurem, concretamente, o desempenho correto e ordenado dessa mesma função. Esses poderes - implícitos e instrumentais - são os inherent powers. 
É nesse sentido, precisamente, que se deve entender a ideia no common law, de que o contempt of court é um poder inerente aos órgãos jurisdicionais. (1999, p.92)

Essa visão da jurisdição e dos poderes decorrentes da mesma está pautada na crença da plena dominação do direito, que não pode ser vista de um modo meramente simbólico ou submerso na burocracia de procedimentos que permitam ao particular negar-se legitimamente a dar cumprimento à lei. Assim ensina Michele Taruffo:

[....] há muitas situações, como aquelas que foram recordadas anteriormente, nas quais o instrumento injunction/contempt representa o único modo eficaz para uma tutela não só nominalística de novos direitos "substanciais", como, também, para manter a fundamental supremacia da lei, evitando, assim, abusos, omissões e obstruções, direcionadas a reduzir a nada o direito afirmado no pronunciamento do Juiz. (1990, p.77)

Dentro do contexto mencionado das injunctions foi que a jurisprudência do common law deu-se conta dos problemas relacionados à efetivação dos provimentos em relação às pessoas jurídicas, o que denominou-se de institutional litigation, por terem sua "vontade" dificilmente atingida para que os meios coercitivos tenham efeito e principalmente no que concerne às já mencionadas obrigações complexas e de trato sucessivo. Assim foram surgindo técnicas de caráter sub-rogatório para a execução de tais obrigações, como expõe Marcelo Guerra:

Essas técnicas orientam-se todas, de um modo geral, no sentido de ampliar a utilização de terceiros nomeados especialmente pelo órgão jurisdicional para desempenhar funções auxiliares da justiça, a fim de que, dessa maneira, mesmo as atividades complexas e de trato sucessivo do devedor possam ser substituídas por aquela do órgão jurisdicional, proporcionando ao credor o resultado prático equivalente ao cumprimento. (2003, p. 121)

É inegável a influência das mencionadas técnicas em nosso direito, ficando visível a inspiração nas mesmas quando da reforma legislativa de 1994 (Lei $\mathrm{n}^{\circ}$ 8952/94), que alterou a execução das obrigações de fazer e não fazer, reconhecendo o caráter mandamental desses provimentos (art. 14 do CPC) e instituindo a atipicidade dos meios executivos (art. $461, \S 5^{\circ}$, do CPC) para atingir a tutela específica. (GRINOVER; WATANABE, 2006)

Fincadas as premissas históricas e definida a plena aplicabilidade da intervenção judicial como meio executivo das obrigações de fazer e não fazer, passaremos a um estudo mais pragmático do instituto, de modo a identificar os seus contornos em nossa legislação. A intervenção judicial é definida por Cretella Júnior do seguinte modo: 
Intervenção é a ingerência, ingresso ou incursão de entidade "de maior grau" na "esfera de negócios" da entidade "de grau menos elevado". Determinando, em despacho motivado a ingerência, quando indispensável para permitir a execução específica da obrigação, o juiz procede também à nomeação do interventor. (1996, p. 129)

Estando o juiz diante de caso concreto em que condena pessoa jurídica a obrigações complexas e entendendo ser a intervenção judicial o meio executivo mais adequado, deve primeiro dar ao devedor a possibilidade de adimplemento espontâneo (ARENHART, 2010). Porém, para levar-se em conta o real intuito do devedor em adimplir, deve ser exigido dele plano de ação e posteriores provas do efetivo cumprimento, visto que a simples espera do adimplemento para só depois decretar a intervenção pode trazer dificuldades ao cumprimento e risco de inefetividade da execução. Esta fase também é importante, pois a iminência da decretação da intervenção pode coagir o devedor a adimplir, consistindo assim a intervenção como meio executivo de caráter tanto coercitivo quanto sub-rogatório. Sobre a questão escreve Sérgio Cruz Arenhart:

Esse papel coercitivo pode ser visto quando se tem a imagem do ordenado que deve escolher entre resistir à ordem judicial - e ver um interventor ser colocado em seu lugar, com poderes de administração maiores ou menores, mas com acesso a informações sigilosas, à vida da empresa e com a possibilidade de não conseguir conduzir os negócios com a mesma perícia do proprietário ou cumprir, ele mesmo, a decisão do juiz. Normalmente, só essa visão já será suficiente para estimular o ordenado a optar pela segunda alternativa, evitando assim a ingerência de um desconhecido em seus assuntos e mantendo consigo a gestão de seu trabalho. (2010, p. 7)

Quanto às espécies de intervenção, a doutrina as classifica em três tipos: fiscalizatória, cogestora e substitutiva. A primeira, obviamente, tem o sentido de fiscalizar o cumprimento da ordem judicial ou o andamento de determinados assuntos da corporação, podendo, inclusive, ser decretada em segredo de justiça. Já na intervenção cogestora o interventor assume apenas uma parcela das atribuições de administração da empresa. Na última espécie ocorre a real expropriação temporária do controle da empresa em benefício do interventor para que dê cumprimento às ordens do juiz. Em caso de obstrução por parte dos integrantes da pessoa jurídica em colaborar com o interventor nos casos de intervenção fiscalizatória ou cogestora, poderá ser modificada para a intervenção substitutiva, ocorrendo a tomada de controle administrativo completo. (ARENHART, 2010)

Não havendo o adimplemento espontâneo, o juiz nomeará interventor que goze de aptidão técnica para as tarefas a serem executadas e idoneidade moral, em decisão motivada em que fixará claramente as atribuições 
e ações que serão desenvolvidas pelo interventor dentro da corporação (art. 69 da Lei 8.884/94). O devedor poderá impugnar a nomeação do interventor por motivos de aptidão técnica e idoneidade moral, exceto no caso das intervenções fiscalizatórias que podem ser decretadas em sigilo, no prazo de 48 horas com três para as razões (art. 70 da Lei). O juiz julgará a impugnação e em caso de procedência nomeará outro interventor no prazo de cinco dias (art. 71).

A intervenção é medida de caráter temporário, tendo a lei antitruste fixado o prazo máximo de 180 dias para a sua execução (art. 73). Porém, esse prazo deve ser tido apenas como um parâmetro, visto que a própria lei, no art. 77, prevê que depois de findo o prazo assinalado, caso não tenha havido cumprimento total da ordem, haverá prorrogação. Portanto, o término da medida vinculase apenas ao cumprimento da intervenção, que quando alcançado revogará imediatamente a execução (art. 72). No entanto, ante a agressividade da medida, a cada 180 dias deverá o interventor produzir relatório extraordinário, além dos mensais já exigidos pelo art. 75, III, sobre o qual o juiz deverá se pronunciar sobre a continuidade da intervenção, na forma do art. 77, garantindo o contraditório e a legitimidade da execução.

O interventor tem o dever de atuar buscando a execução da ordem judicial, dentro de seus limites, e relatará ao juiz todo e qualquer embaraço à sua atividade (art. 75). Diante da falta de cooperação de um agente corporativo, o magistrado o afastará de suas atividades, sendo o mesmo substituído na forma do estatuto (art. 74). Em persistindo a resistência na cooperação ou tornando-se a mesma generalizada, ocorrerá a expropriação da administração da empresa, decretando-se intervenção substitutiva $\left(\right.$ art. $74, \S 2^{\circ}$ ), ressalvada a responsabilidade criminal dos agentes resistentes (art. 78), pelos crimes de resistência, desobediência e coação no curso do processo, previstos respectivamente nos arts. 329, 330 e 344 do Código Penal Brasileiro.

O interventor responderá por quaisquer abusos na condução da intervenção e será obrigatoriamente substituído caso torne-se civilmente insolvente, quando for sujeito ativo ou passivo de corrupção ou prevaricação e quando não observar seus deveres $\left(\operatorname{art.} 73, \S 2^{\circ}\right)$. Na administração da corporação deverá observar também o que dispõe da Lei das Sociedades Anônimas (Lei $n^{0}$ 6404/76), principalmente nos arts. 153 a 159, que dispõe dos deveres do administrador, mesmo que a intervinda não tenha esse tipo societário, por força do art. $73, \S 1^{\circ}$, da Lei 8.884/94. Ainda no campo da responsabilidade, na falta de previsão na lei antitruste, o magistrado poderá utilizar-se das disposições concernentes ao administrador ou depositário por analogia, que tem previsão no Código de Processo Civil, arts. 148 a 150, dentre outros, inclusive no concernente à sua remuneração. (ARENHART, 2010) 
Percebemos, então, que a legislação possui regulação bastante farta do instituto, o que não significa, no entanto, que o magistrado esteja completamente vinculado a estes ditames, ante o caráter de meio executivo atípico, visto que do contrário incorrer-se-ia no mesmo problema antes mencionado da imprevisibilidade das situações práticas e a necessária adequação ao caso concreto.

Vale ressaltar, também, que a intervenção judicial pode ser utilizada em vários momentos do processo, nos quais o juiz necessite garantir o adimplemento de provimento mandamental, como em sede de cautelar ou tutela antecipada, tutela inibitória ou de remoção do ilícito e até como medida executiva auxiliar a outras já empregadas na execução.

\section{F_A IntervenÇão Judicial na ExecuÇão doS Novos Direitos}

Do que se expôs até agora, acreditamos ter ficado claro estar a ciência processual atual alerta para uma necessária adequação dos instrumentos processuais aos direitos tutelados e que os "novos direitos" necessitam de cuidado especial do processualista, como também, aclaramos a existência da intervenção judicial como meio executivo, dentro dos moldes estudados, com esteio nos arts. $461, \S 5^{\circ}$, do CPC e 84 do CDC.

Neste capítulo pretendemos finalizar com o estudo da jurisprudência sobre o tema e pensar alguns casos em que os "novos direitos" demandam a intervenção judicial como meio executivo.

Como já exposto anteriormente, há grande necessidade de uma maior exploração da intervenção judicial. Percebe-se isso diante da escassa e restritiva jurisprudência do STJ abordando diretamente a temática. Assim dispõe um dos julgados da corte:

CONFLITO DEATRIBUIÇÃO - INTERVENÇÃO JUDICIAL DECRETADAEM INSTITUIÇÃO FINANCEIRA FEDERAL - DESTITUIÇÃO TEMPORÁRIADE PRESIDENTE E NOMEAÇÃO DE SUBSTITUTO PARA CUMPRIMENTO DE DECISÃO JUDICIAL - ILEGALIDADE - CONFLITO PROCEDENTE.

I - A determinação do Juízo de Direito da Comarca de Jaguaruana, em decretar a intervenção no Banco do Nordeste do Brasil S. A. - BNB, com a substituição do seu presidente por funcionário do Banco Central do Brasil, é completamente ilegal, extrapolando os limites estabelecidos em lei para a execução do julgado. Não há previsão legal para esse tipo de intervenção, em casos de execução de um julgado numa ação de indenização.

II - A execução da tutela antecipatória, na forma pretendida, não somente extravasa os poderes do Magistrado, como também adentra a esfera administrativa de atribuições de autoridade administrativa, a quem compete nomear e demitir o Presidente do BANCO DO NORDESTE DO BRASIL S. A. - BNB, no caso, o Excelentíssimo Senhor Presidente da República. 
III - Conflito de atribuição procedente.

(STJ - Cat 51/DF - 2 ${ }^{\mathrm{a}}$ seção - Rel. Min. Massami Uyeda-Dje 23.11.2009)

Desta decisão percebemos duas posições do STJ: uma entendendo inaplicável quanto às obrigações de pagar e outra se posicionando pela inaplicabilidade da intervenção ao poder público, visto que se trataria de usurpação de competência afastar do cargo um agente público.

A primeira posição tem amparo na legislação processual positiva, pois como já expomos, temos um sistema misto de meios executivos, aplicando-se apenas meios típicos para a cobrança de obrigações de pagar. Não obstante ser extremamente discutível tal posição, visto que já observamos que a atipicidade dos meios executivos não decorre da lei, mas de poderes implícitos concedidos ao magistrado para efetivar o acesso à justiça e aos direitos fundamentais, não atinge o âmbito desse estudo, que está enfocado nas obrigações de fazer e não fazer.

Já a segunda posição do STJ nos parece absurda, pois a intervenção é medida executiva e como tal tem caráter temporário, operando-se até o adimplemento, não consistindo, portanto, em nomeação ou destituição real do cargo, pois a administração voltará à composição original quando findo o procedimento. Não é o caso, no entanto, dos agentes políticos propriamente ditos, pois para estes a Constituição Federal dispõe forma de intervenção específica nos arts. 34 a 36. (ARENHART, 2010)

A jurisprudência trabalhista, no entanto, mostra-se bem avançada no tema aplicando a intervenção judicial em vários casos, sendo emblemática a intervenção na companhia aérea VASP, determinada pelo juiz da $14^{\text {a }}$ Vara do Trabalho de São Paulo, para garantir o adimplemento dos créditos trabalhistas e a regularidade da falência.

Cabe agora, para ilustrar e tornar mais concreta a aplicação da intervenção, mencionar algumas hipóteses dos novos direitos onde se mostraria promissora a intervenção judicial.

$\mathrm{Na}$ seara trabalhista ela é necessária para garantir a reintegração do trabalhador com garantia de emprego, evitar o assédio moral no ambiente empresarial, implementar condições de saúde e segurança do trabalho e impedir discriminação ilegal no momento da contratação de empregados.

Na proteção ao consumidor utiliza-se a intervenção para impedir práticas lesivas à concorrência do mercado como holding, truste e cartel, garantir informação completa dos produtos e serviços, fiscalizar o atendimento ao consumidor e verificar linhas de produção de produtos viciados e nocivos ao consumo.

Contra a administração pública pode ser muito utilizada em sede de mandado de segurança, ações que visem efetivar benefícios previdenciários, implementar benefícios em folha de pagamento de servidor público, entre outras 
ocasiões em que seja necessário evitar que a burocracia administrativa seja uma desculpa para o agente público não efetivar provimentos mandamentais.

No direito ambiental a intervenção é profícua na prevenção de danos ambientais e na reparação, se intervindo na produção e no descarte de dejetos industriais.

No direito da criança e do adolescente, ela é utilizada para evitar os maus-tratos em unidades de internação ou orfanatos, o que se aplica também aos idosos nos asilos e às adaptações necessárias nos ambientes públicos para sua circulação.

Na proteção dos portadores de necessidades especiais, para garantir seu acesso aos locais públicos e eventos em geral, bem como o número de vagas determinado por lei em órgãos públicos e grandes empresas.

A lista apontada traz apenas alguns poucos exemplos, dentro da grande gama de situações que necessitam de uma atuação judicial para sua efetivação e que muitas vezes são negligenciadas judicialmente pela inefetividade dos meios executivos tradicionais.

\section{Considerações Finais}

As considerações feitas sobre os "novos direitos" e sobre o real acesso à justiça devem ser levadas em conta, como um necessário comprometimento que deve ter o magistrado com a eficácia dos direitos fundamentais, pois não devemos cair no risco de termos "direitos simbólicos", como alerta Galanter:

O sistema tem a capacidade de mudar muito ao nível do ordenamento sem que isso corresponda a mudanças na prática diária da distribuição de vantagens tangíveis. Na realidade, a mudança de regras pode tornar-se um substituto simbólico para a redistribuição de vantagens (1974, p.149, apud CAPELLETI; GARTH, 1988, p. 68)

Nesse sentido, não podemos permitir que o processo seja um agente da manutenção do status quo e da dominação do economicamente mais forte, trazendo a completa negação do direito material que estaria se tornando um objeto de retórica para o controle das massas.

O processo deve sempre ser o sistema adequado para a obtenção real das vantagens decorrentes do direito material, visto que esta é sua função precípua e para tanto é imprescindível o reconhecimento de meios executivos tais qual a intervenção judicial, que se mostrem campo fértil para o florescimento dos direitos fundamentais. 


\section{REFERÊNCIAS}

Abi-Eçab, Pedro. Transversalidade dos princípios dos direitos metaindividuais. Revista de Direito Privado, São Paulo, v. 9, n. 36, p. 278-295, out-dez. 2008. ANDREWS, Neil. Injunctions in support of civil proceedings and arbitration. Revista de processo, São Paulo, v. 34, n. 171, p. 165 a 192, mai. 2009.

ARENHART, Sérgio Cruz. A Intervenção Judicial e o Cumprimento da Tutela Específica. Disponível em: <http://ufpr.academia.edu/SergioCruzArenhart/ Blog >. Acesso em: 23 abr. 2010.

BEDAQUE, José Roberto dos Santos. Direito e processo: influência do direito material sobre o processo. 5. ed. São Paulo: Malheiros, 2009.

CANOTILHO, José Joaquim Gomes. Direito Constitucional e Teoria da Constituição. 7. ed. Coimbra: Almedina, 2003.

CAPELLETI, Mauro; GARTH, Bryant. Acesso à justiça. Tradução de Ellen Gracie Northfleet. Porto Alegre: Fabris, 1988.

Cretella Júnior, José. Comentários à Lei Antitruste. Rio de Janeiro: Forense, 1996.

DWORKIN, Ronald. O Império do direito. 2. ed. São Paulo: Martins Fontes, 2007.

GUERRA, Marcelo Lima. Direitos Fundamentais e a Proteção do Credor na Execução Civil. São Paulo: RT, 2003.

GUERRA, Marcelo Lima. Execução Indireta. 2. ed. São Paulo: RT, 1999.

GRINOVER, Ada Pellegrini; WATANABE, Kazuo. Recepção e transmissão de institutos processuais civis. Revista de processo, São Paulo, v.31 n.140, p.143 a 154 , out. 2006 .

MARINONI, Luiz Guilherme. Da Ação Abstrata e Uniforme à Ação Adequada à Tutela dos Direitos. In: NERY JÚNIOR, Nelson; WAMBIER, Teresa Arruda Alvim; FUX, Luiz (Organizadores). Processo e constituição: estudos em homenagem ao Professor José Carlos Barbosa Moreira. São Paulo: RT, 2006.

MATTOS, Lucas de Brandão e. Aplicação do art. 475-J do CPC à Execução Trabalhista. Revista Jurídica da FA7: Periódico científico e cultural do Curso de Direito da Faculdade 7 de Setembro, Fortaleza, v. 6, n. 1, p. 261-274, abr. 2009.

TARUFFO, Michelle. A atuação executiva dos direitos: perfis comparatísticos. Tradução de Teresa Arruda Alvim Wambier. Revista de Processo, São Paulo, v. 15, n. 59, p. 72-97, jul-set. 1990. 


\section{JUDICIAL INTERVENTION AS PROTECTION TO NEW RIGHTS}

Resumo: This study focuses on judicial intervention, a less known executive mean although regulated by Brazilian law. It aims to demonstrate how effective its application is, mainly when concerning the so-called "new rights", which imposes quite complex obligations to perform or not to perform, generally by juridical persons.

Keywords: Judicial intervention. Execution effectiveness. New rights. Atypical executive means.

Data de recebimento: jan/2011 - Data de aprovação: mar/2011 